\title{
PENGGUNAKAN KUESIONER SNQ UNTUK ANALISIS KELUHAN RASA SAKIT YANG DIALAMI PEKERJA PADA UKM KERUPUK DI KOTA MEDAN
}

\author{
Rosnani Ginting ${ }^{1}$, Alfin F. Malik ${ }^{2}$ \\ ${ }^{1,2}$ Departemen Teknik Industri, Universitas Sumatera Utara (USU) \\ Jl. Almamater, Kampus USU Medan 20155 Indonesia \\ Email : rosnani_usu@yahoo.co.id \\ Email : alfin_fauzi_malik@yahoo.co.id
}

\begin{abstract}
Abstrak. Usaha Kecil Menengah (UKM) merupakan sumber ekonomi potensial di masyarakat yang mampu menggerakkan roda ekonomi sampai pada tataran masyarakat bawah. Berbagai keunggulan yang ada di UKM terdapat juga hal-hal yang perlu ditingkatkan salah satunya adalah metode kerja pekerja. UKM Kerupuk Ikan dan UKM Raos yang memproduksi kerupuk juga merupakan UKM yang perlu mendapatkan perbaikan pada sistem kerjanya. Standard Nordic Questionnaire (SNQ) merupakan alat yang dapat mengetahui bagian-bagian otot yang mengalami keluhan dengan tingkat keluhan mulai dari Tidak Sakit (TS), agak sakit (AS), Sakit (S) dan Sangat Sakit. Perbaikan diawali dengan mengidentifikasi keluhan operator melalui penyebaran kuisioner Standard Nordic Questionnaire (SNQ). Hasil dari identifikasi ini diketahui para operator mengalami keluhan Musculoskeletal Disorders (MSDs). Kondisi ini terjadi dikarenakan seringnya pekerja bekerja dengan postur kerja yang janggal, yaitu postur membungkuk, duduk dan jongkok. Postur kerja ini memicu timbulnya gangguan pada otot, kesemutan, pegal, dan sakit pada sendi sehingga meninbulkan keluhan-keluhan operator. Keadaan ini mengindikasikan bahwa aktivitas tersebut tergolong kedalam kategori berbahaya dan dapat menyebabkan risiko MSDs. Melihat kondisi di UKM ini dilakukanlah penelitian untuk mengetahui keluhan yang dirasakan pekerja dan selanjutnya dilakukan analisis dan perbaikan aktivitas serta postur kerja. Hal ini sebagai upaya untuk mengurangi MSDs dan keluhan-keluhan yang dirasakan oleh pekerja selama bekerja.
\end{abstract}

\section{Keywords: UKM, Produksi Kerupuk, Kuisioner Standard Nordic Questionnaire (SNQ)}

\section{Pendahuluan}

Pekerjaan yang dilakukan secara manual dengan postur kerja yang tidak alamiah dapat menimbulkan keluhan seperti pegal, kesemutan, dan nyeri pada tulang. Kondisi seperti ini akan berakibat pada timbulnya penyakit akibat kerja yaitu penyakit otot rangka atau Musculoskeletal Disorders (MSDs). MSDs berpengaruh signifikan pada pekerja yang menyebabkan sakit, nyri, mati rasa, kesemutan, bengkak, kekakuan, gemetar, gangguan tidur dan rasa terbakar. Menurut OSHA, MSDs adalah cidera atau gangguan pada jaringan lunak (seperti otot, tendon, ligament, sendi, dan tulang rawan) dan sistem saraf dimana cidera atau gangguan ini dapat mempengaruhi hampir semua jaringan termasuk saraf dan sarung tendon (Laraswati, 2009). Selanjutnya Peter Vi (2002) dalam Pratiwi (2010) menjelaskan bahwa, terdapat beberapa faktor yang dapat menyebabkan terjadinya keluhan otot skeletal, yaitu: 1) Peregangan otot yang berlebihan, 2) Aktivitas berulang, 3) Postur kerja tidak alamiah, 4) Faktor penyebab skunder, diantaranya: tekanan, getaran, mikrolimat, dan 5) Penyebab kombinasi, diantaranya: umur, jenis kelamin, kebiasaan merokok, kesegaran jasmani, kekuatan fisik, ukuran tubuh (antropometri).

UKM Kerupuk Ikan dan UKM Raos memiliki masalah pada pekerja sehingga menggunkan Body Map Kuisioner pada pekerja untuk melihat keluhan kelelahan pekerja pada fasilitas kerja pada proses produksi. Melihat kondisi di UKM ini dilakukanlah penelitian untuk mengetahui keluhan yang dirasakan pekerja dan selanjutnya dilakukan analisis dan perbaikan aktivitas serta postur kerja. Hal ini sebagai upaya untuk mengurangi MSDs dan keluhan-keluhan yang dirasakan oleh operator selama bekerja.

\section{Landasan Teori}

\subsection{Keluhan Musculoskeletal}

Keluhan musculoskeletal adalah keluhan pada bagian-bagian otot skeletal yang dirasakan oleh seseorang mulai dari keluhan sangat ringan sampai sangat sakit. Apabila otot menerima beban statis secara berulang dalam waktu yang lama, akan dapat menyebabkan keluhan berupa kerusakan pada sendi, ligamen dan tendon. Keluhan hingga kerusakan inilah yang biasanya diistilakan dengan 
Musculoskeletal disorsders (MSDs) atau cedera pada sistem muskuloskeletal. Apabila pekerjaan berulang tersebut dilakukan dengan cara yang nyaman, sehat dan sesuai dengan standar yang ergonomis, maka tidak akan menyebabkan gangguan muskuloskeletal dan semua pekerjaan akan berlangsung dengan efektif dan efisien. Secara garis besar keluhan otot yang terjadi dapat dikelompokkan menjadi dua yaitu:

1. Keluhan sementara (reversible), yaitu keluhan otot yang terjadi pada saat menerima beban statis, namun demikian keluhan tersebut akan hilang apabila pembebanan dihentikan.

2. Keluhan menetap (persistent), yaitu keluhan otot yang bersifat menetap. Walaupun pembebanan kerja telah dihentikan, namun rasa sakit pada otot masih terus berlanjut

Peter vi (2000) menjelaskan bahwa, terdapat banyak faktor yang dapat menyebabkan terjadi keluhan musculoskeletal sebagai berikut:

1. Peregangan otot yang berlebihan

Peregangan otot yang berlebihan pada umumnya sering dikeluhakan oleh para pekerja dimana aktivitas kerjanya menuntut pengerahan tenaga yang besar seperti aktivitas mengangkat, menarik, mendorong dan menahan beban yang berat

2. Aktivitas berulang

Aktivitas berulang merupakan pekerjaan yang dilakukan secara terus menerus seperti pekerjaan mencangkul, membelah kayu besar, angkut dan sebagainya. Keluhan otot terjadi karena otot menerima tekanan akibat beban kerja secara terus menerus tanpa memperoleh kesempatan untuk relaksasi.

3. Sikap kerja tidak alamiah

Sikap kerja tidak alamiah adalah sikap kerja yang menyebabkan posisi bagian bagian tubuh bergerak menjauhi posisi alamiah, misalnya pergerakan tangan terangkat, punggung terlalu membungkuk, kepala terangkat dan sebagainya

4. Faktor penyebab sekunder

Faktor penyebab sekunder ini adalah berupa tekanan langsung dari jaringan otot yang lunak atau getaran dengan frekwensi tinggi yang menyebabkan kontraksi otot bertambah.

Pengukuran terhadap tekanan fisik ini cukup sulit karena melibatkan berbagai faktor subjektif seperti kinerja, motivasi, harapan dan toleransi kelelahan. Alat ukur yang digunakan dpat dilakukan dengan berbagai cara mulai metoda yang sederhana sampai menggunakan sistem komputer. Salah satu dari metode tersebut adalah melalui Standard Nordic Questionnaire.

\subsubsection{Komponen Sistem Database}

Komponen Sistem Database meliputi:

1. Data

Data adalah representasi fakta dunia nyata yang mewakili suatu obyek (spt, manusia: dosen, mhs, pelanggan,dll; barang: buku, meja; peristiwa, konsep, dsb.), yang direkam baik dalam bentuk angka, huruf, teks, gambar atau suara. Dalam sistem database, data harus bersifat:

a. Dipakai bersama

Masing-masing bagian dari database dapat diakses oleh pemakai lebih dari satu orang dalam waktu yang bersamaan, untuk aplikasi yang berbeda.

b. Terintegrasi / terpadu

Database merupakan kumpulan dari berbagai macam file dari aplikasiaplikasi yang berbeda, yang disusun dengan cara menghilangkan bagian-bagian yang rangkap (redundant).

2. Perangkat keras (Hardware)

Perangkat keras yang dibutuhkan dalam sistem database harus memenuhi spesifikasi yang dibutuhkan untuk menjalankan perangkat lunak, agar perangkat lunak sistem database bisa berjalan dengan baik.

3. Perangkat lunak (Software)

Perangkat lunak dalam sistem database berfungsi sebagai perantara (interface) antara pemakai dengan data fisik pada database. Software pada sistem database dapat berupa:

a. Database Management System (DBMS), yang menangani akses terhadap database, sehingga pemakai tidak perlu memikirkan proses penyimpanan dan pengelolaan data secara detail.

b. Program-program aplikasi dan prosedurprosedur perangkat lunak yang digunakan dalam sistem database harus menyediakan fasilitas - fasilitas sebagai berikut:

1) Membuat file

2) Menyisipkan data

3) Menampilkan data

4) Menghapus data

5) Kontrol keamanan

6) Kontrol keterpaduan

4. Pemakai (User)

Pemakai database dibagi atas 3 klasifikasi, yaitu:

a. Database Administrator (DBA), yaitu: Orang/team yang bertugas mengelola sistem database secara keseluruhan.

b. Programmer, yaitu: 
Orang/team yang bertugas membuat program aplikasi yang mengakses database, dengan menggunakan bahasa pemrograman, seperti Clipper, VB, Oracle baik secara bath maupun online untuk berinteraksi dengan komputer.

c. End-user, yaitu:

Orang yang mengakses database melalui terminal, dengan menggunakan querylanguage atau program aplikasi yang dibuatkan oleh programmer.

\subsection{Standard Nordic Questionnaire}

Standard Nordic Questionnaire (SNQ) merupakan alat yang dapat mengetahui bagianbagian otot yang mengalami keluhan dengan tingkat keluhan mualai dari Tidak Sakit (TS), agak sakit (AS), Sakit (S) dan Sangat Sakit (SS). Dengan melihat dan menganalisis peta tubuh maka dapat diestimasi jenis dan tingkat keluhan otot skeletal yang dirasakan oleh pekerja. SNQ merupakan suatu instrumen untuk menilai segmen-segmen tubuh yang dirasakan operator (menurut persepsi operator), apakah sangat sakit, sakit, agak sakit, dan tidak sakit. Pekerjaan ini dilakukan secara manual dengan sikap kerja yang tidak alamiah serta dilakukan dalam waktu yang lama, yaitu selama 8 jam kerja.

\section{Proses Produksi Pembuatan Kerupuk}

Urutan proses produksi kerupuk pada UKM

Raos adalah sebagai berikut :

1. Membuat adonan untuk pencetak

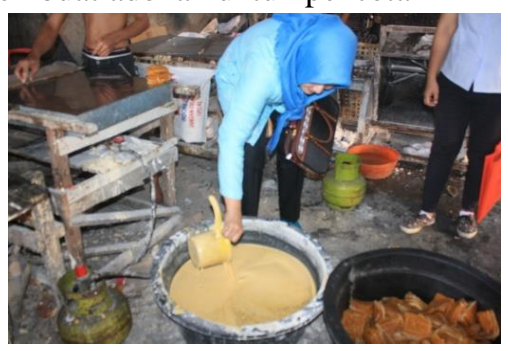

2. Dilakukan pencetakan kerupuk

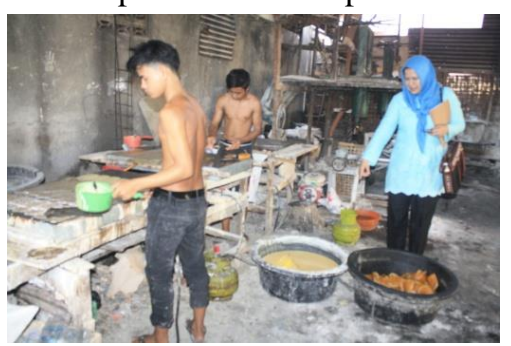

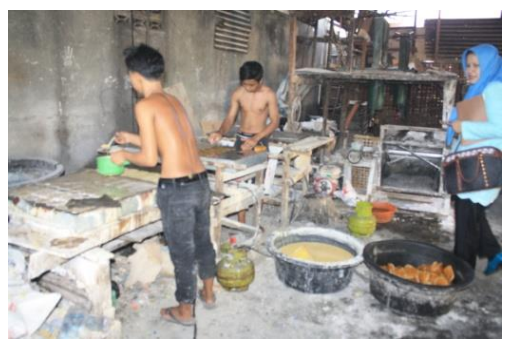

3. Setelah dicetak dilakukan pengukusan kerupuk selama 5 menit

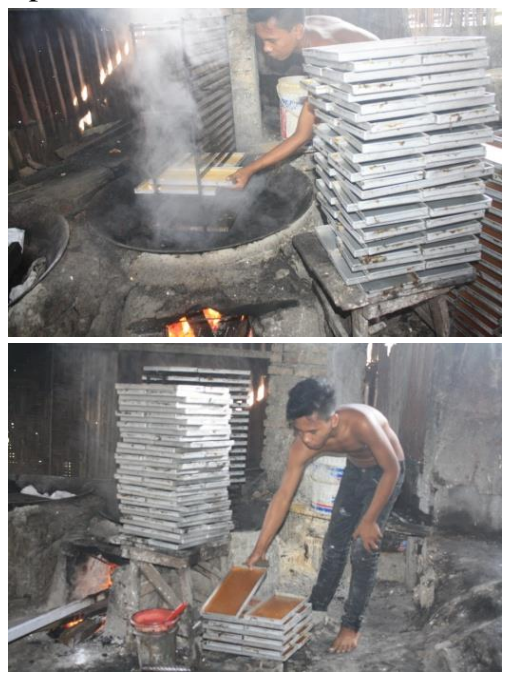

4. Setelah dikukus kemudian kerupuk dijemur dengan panas matahari selama 1-2 hari

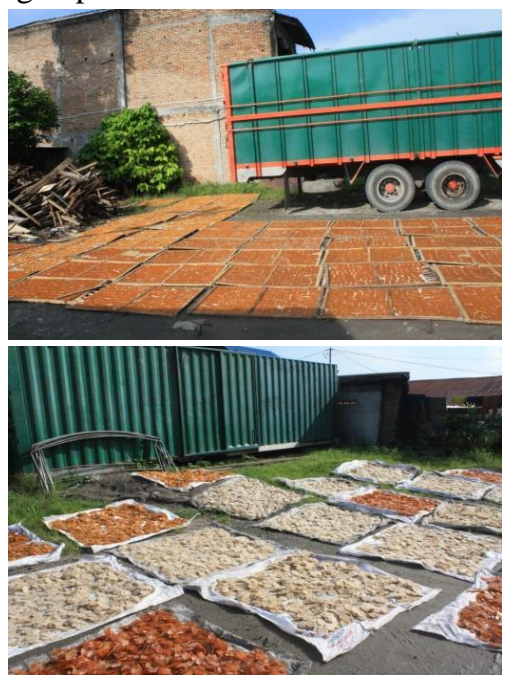

5. Kerupuk yang sudah kering dijemur kemudian digoreng

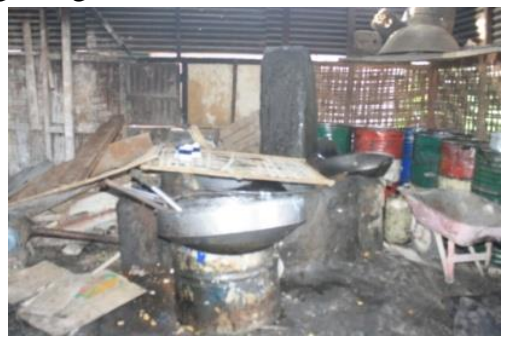




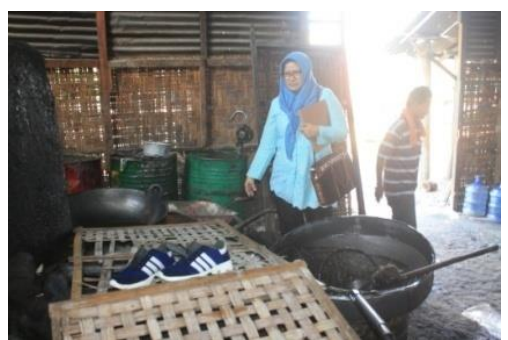

6. Dilakukan pengemasan produk dan produk siap dipasarkan

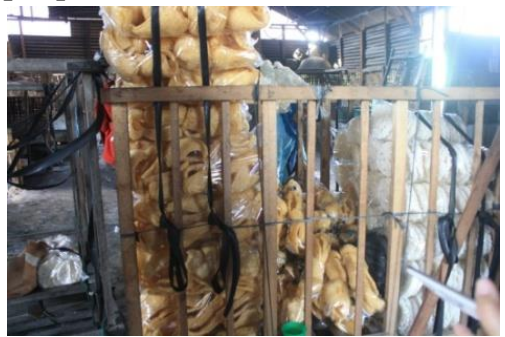

Urutan proses produksi kerupuk pada UKM kerupuk Ikan adalah sebagai berikut :

1. Membuat adonan untuk dilakukan pencetakan setelah dicampur dengan bumbu kemudian diaduk dengan mixer.

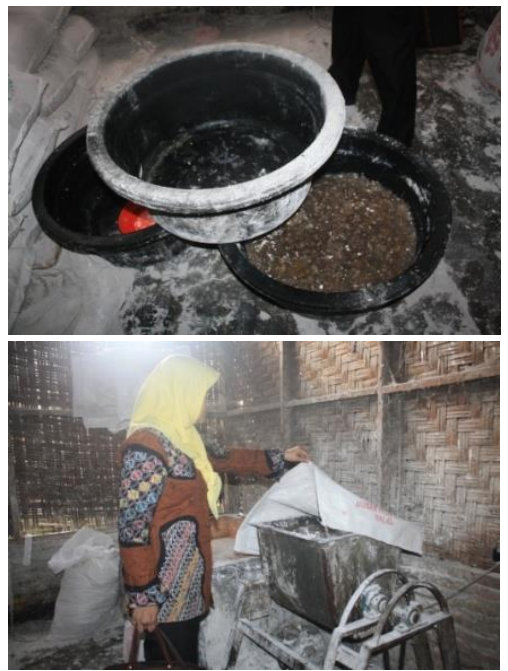

2. Dilakukan pencetakan kerupuk

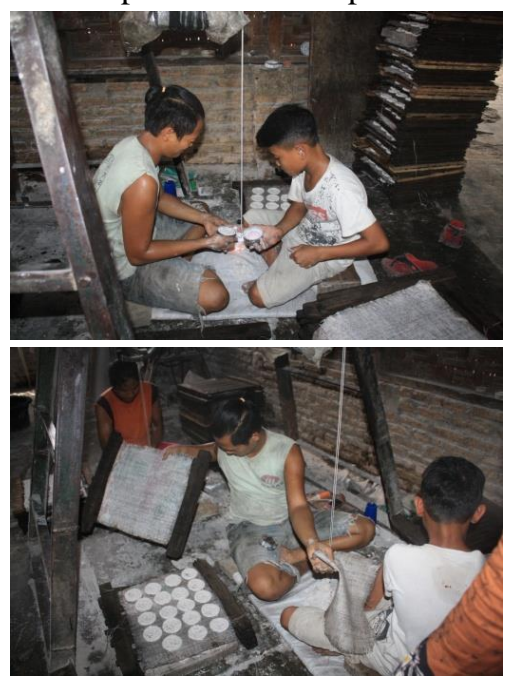

3. Setelah dicetak dilakukan pengukusan kerupuk yang berlangsung selama 10-15 menit

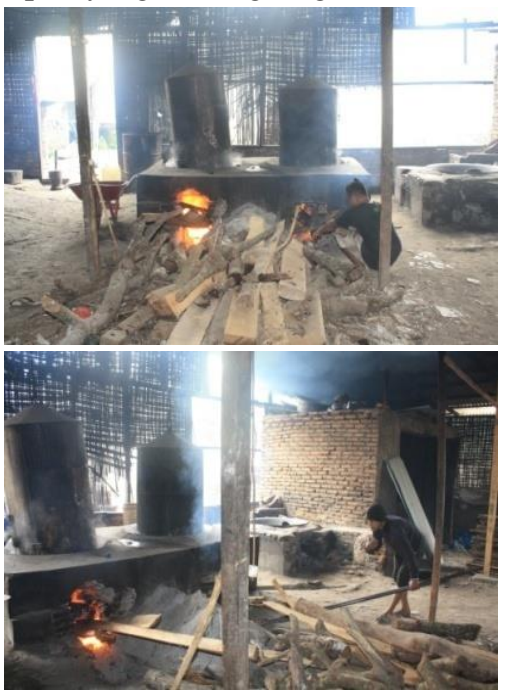

4. Setelah dilakukan pencetakan kemudian kerupuk dijemur dengan panas matahari selama 1 hari

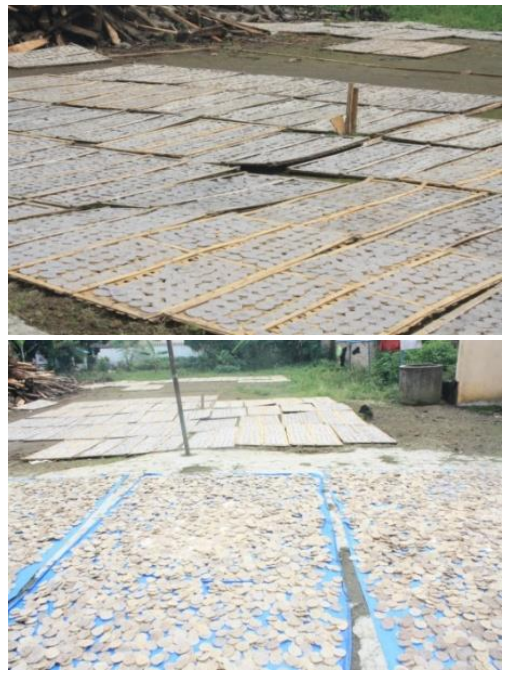

5. Setelah dijemur kemudian dilakukan pengasapan agar kerupuk lebih kering selama 5 menit

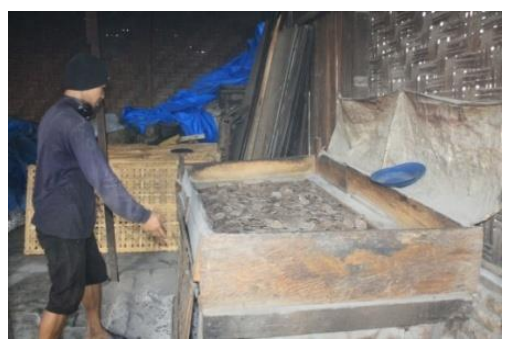

6. Kerupuk yang sudah kering dijemur kemudian digoreng 


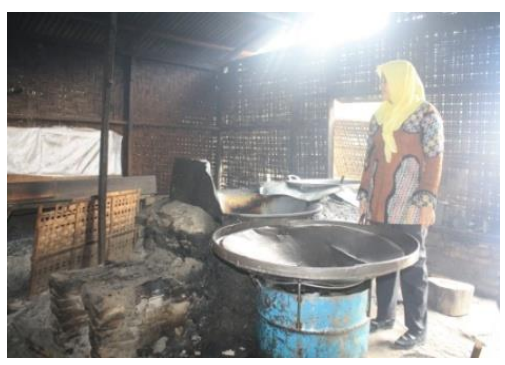

7. Dilakukan pengemasan produk dan produk siap dipasarkan

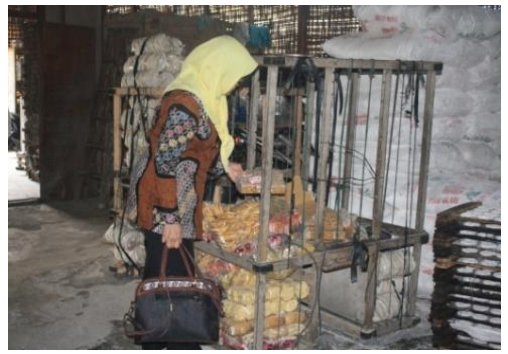

\section{Metode Pelaksanaan}

Penelitian dilakukan dengan observasi di tempat kerja dengan sasaran yang meliputi pekerja dan fasilitas kerjanya. Tahap pertama pengambilan data adalah dengan menyebar kuesioner Standard Nordic Questionnaire (SNQ) untuk mengetahui pada bagian tubuh mana operator merasakan keluhan. Pada tahap ini akan dihitung tingkat resiko tertinggi pada operator.

\section{Hasil dan Pembahasan \\ 5.1. Body Map Kuisioner}

Data ini didapatkan melalui penyebaran kuesioner SNQ. Data ini ditujukan untuk mengetahui bagian tubuh operator yang mengalami keluhan sewaktu melakukan aktivitasnya. Data hasil penyebaran Standard Nordic Questionnaire diberi penilaian atau pembobotan untuk masingmasing kategori sebagai berikut:

$\begin{array}{ll}\text { Tidak sakit } & \text { : bobot } 0 \\ \text { Agak sakit } & \text { : bobot } 1 \\ \text { Sakit } & \text { : bobot } 2 \\ \text { Sangat sakit } & \text { : bobot } 3\end{array}$

Kuisioner SNQ diberikan kepada 6 orang operator dan terdiri dari pertanyaan ke-0 hingga ke27

0 : Leher Bag. Atas

1 : Leher Bag. Bawah

2 : Bahu Kiri

3 : Bahu Kanan

4 : Lengan Atas Kiri

5 : Punggung

6 : Lengan Atas Kanan

7 : Pinggang

8 : Punggung

9 : Pantat

10 : Siku Kiri

11 : Siku Kanan

12 : Lengan Bawah Kiri

13 : Lengan Bawah Kanan
14 : Pergelangan Tangan Kiri

15 : Pergelangan Tangan Kanan

16 : Telapak Tangan Kiri

17 : Telapak Tangan Kanan

18 : Paha Kiri

19 : Paha Kanan

20 : Lutut Kiri

21: Lutut Kanan

22 : Betis Kiri

23 : Betis Kanan

24 : Pergelangan Kaki Kiri

25 : Pergelangan Kaki Kanan

26 : Telapak Kaki Kiri

27 : Telapak Kaki Kanan

\subsection{Perhitungan Persentase Keluhan Bagian Tubuh}

Setelah dilakukan rekapitulasi skor bobot SNQ pada pengumpulan data dimana diperoleh total skor bobot SNQ sebesar 114. Kemudian data skor rekapitulasi tersebut dirubah kedalam persentase. Untuk mendapatkan persentase tersebut dapat dicari dengan rumus :

$$
\% \text { Keluhan }=\frac{\text { Skor risiko bagian tubuhoperator }}{\text { Jumlah skor risiko bagian tubuhoperator }} \times 100 \%
$$

Contoh: \% Skor Sakit di Leher Bagian Bawah $=\frac{11}{114}=7,92 \%$

Tabel 1. Rekapitulasi Kuesioner SNQ

\begin{tabular}{|c|c|}
\hline Pertanyaan & Persentase \\
\hline 0 & $7,92 \%$ \\
\hline 1 & $3,96 \%$ \\
\hline 2 & $3,96 \%$ \\
\hline 3 & $4,95 \%$ \\
\hline 4 & $3,96 \%$ \\
\hline 5 & $4,95 \%$ \\
\hline 6 & $4,95 \%$ \\
\hline 7 & $8,91 \%$ \\
\hline 8 & $5,94 \%$ \\
\hline 9 & $2,97 \%$ \\
\hline 10 & $1,98 \%$ \\
\hline 11 & $1,98 \%$ \\
\hline 12 & $2,97 \%$ \\
\hline 13 & $2,97 \%$ \\
\hline 14 & $3,96 \%$ \\
\hline 15 & $3,96 \%$ \\
\hline 16 & $3,96 \%$ \\
\hline 17 & $3,96 \%$ \\
\hline 18 & $5,94 \%$ \\
\hline 19 & $5,94 \%$ \\
\hline 20 & $0,00 \%$ \\
\hline 21 & $0,00 \%$ \\
\hline 22 & $0,99 \%$ \\
\hline 23 & $0,99 \%$ \\
\hline
\end{tabular}


Tabel 1. Rekapitulasi Kuesioner SNQ (Lanjutan)

\begin{tabular}{|c|c|}
\hline Pertanyaan & Persentase \\
\hline 24 & $1,98 \%$ \\
\hline 25 & $1,98 \%$ \\
\hline
\end{tabular}

\begin{tabular}{|l|l|}
\hline 26 & $2 \%$ \\
\hline 27 & $2 \%$ \\
\hline
\end{tabular}

Sebaran keluhan secara keseluruhan yang dirasakan oleh operator dapat dilihat dalam histogram

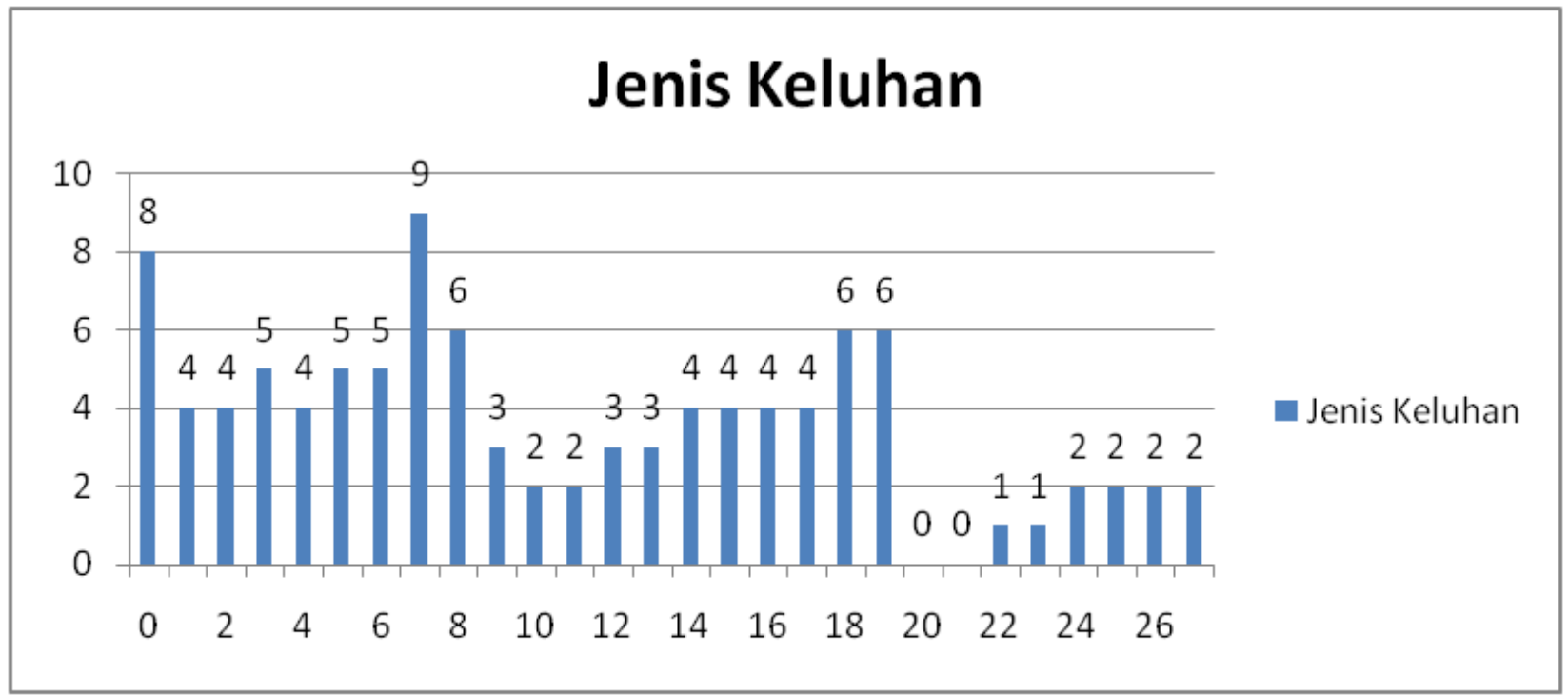

\section{Gambar 1. Histogram Keluhan Operator}

\section{Kesimpulan}

Setelah dilakukan perhitungan persentase keluhan secara keseluruhan, maka diperoleh bahwa rata-rata operator mengalami keluhan terbesar pada bagian tubuh antara lain :

1. Bagian pinggang $(8,91 \%)$

2. Bagian leher bagian atas $(7,92 \%)$

3. Bagian punggung $(5,94 \%)$

4. Bagian betis kiri $(5,94 \%)$

5. Bagian betis kanan $(5,94 \%)$

6. Bagian bahu kanan $(4,95 \%)$

7. Bagian punggung $(4,95 \%)$

8. Bagian lengan kanan atas $(4,95 \%)$

Dengan mengetahui presentasi keluhan yang sering dialami oleh pekerja, maka dapat diberikan sosialisasi kepada para pekerja untuk memperbaiki postur kerja bila perlu dilakukan pengadaan alat untuk membantu operator dalam bekerja.

\section{DAFTAR PUSTAKA}

Ginting, Rosnani. 2007. Sistem Produksi. Yogyakarta: Graha Ilmu

Sinulingga Sukaria, 2008. Pengantar Teknik Industri. Yogyakarta: Graha Ilmu

Sutalaksana, dkk. 1979. Teknik Tata Cara Kerja. Bandung: Penerbit Laboratorium Tata Cara Kerja dan Ergonomi Departemen Teknik Industri ITB.

Wignjosoebroto, Sritomo. 2005. Ergonomi, Studi Gerak dan Waktu. Surabaya: Guna Widya. 